\section{Dengue: inquérito populacional para pesquisa de anticorpos e vigilância virológica no Município de Campinas, São Paulo, Brasil}

\author{
Dengue: sero-epidemiological survey \\ and virological surveillance in Campinas, \\ São Paulo, Brazil
}

\footnotetext{
1 Superintendência de Controle de Endemias, Campinas, Brasil. 2 Secretaria Municipal de Saúde, Prefeitura Municipal de Campinas, Campinas, Brasil.

${ }^{3}$ Faculdade de Medicina de Ribeirão Preto Universidade de São Paulo, Ribeirão Preto, Brasil.

Correspondência V. L. C. Lima Superintendência de Controle de Endemias. Rua São Carlos 546, Campinas, $S P$ 13035-420, Brasil. virgilia@sucen.sp.gov.br
}

\begin{abstract}
The epidemiology of dengue in the municipality of Campinas, São Paulo, Brazil, was studied in 1998 using a randomized sero-epidemiological survey. Epidemiological surveillance data from 1996-2003 were also analyzed, with an emphasis on virological surveillance. 1,260 individuals participated in the survey and had blood samples drawn by finger stick on filter paper. Blood samples were tested by EIA-ICC, an enzyme immunoassay using infected cells as antigen. Dengue antibody prevalence (14.79\%) was lower than in other surveys in other States of Brazil, but higher than in two other serological surveys in São Paulo State. Dengue antibody prevalence was far higher than the reported case incidence during the 1996, 1997, and 1998 epidemics. Antibody prevalence and reported case incidence in different health districts were disproportional. The article concludes by recommending further research on the significance of transmission rates during epidemics and more intensive virological surveillance, especially in years with few reported cases.
\end{abstract}

Dengue; Epidemiologic Surveillance; Serology

\author{
Virgília Luna Castor de Lima 1 \\ Osias Rangel 1 \\ Valmir Roberto Andrade 1 \\ Naoko Yanagizawa Jardim da Silveira 2 \\ Susely Salviano de Oliveira 1 \\ Luiz Tadeu M. Figueiredo ${ }^{3}$
}

\section{Introdução}

O dengue tem se apresentado como importante problema de saúde pública no Brasil. A tendência de ocorrência dessa virose e das suas formas graves é crescente, apesar da oscilação dos níveis de transmissão anuais ao longo das últimas décadas.

Vários estudos têm sido feitos, no país, para esclarecer aspectos da epidemiologia da doença, incluindo, entre esses, inquéritos populacionais visando à detecção dos níveis de anticorpos e, assim, permitindo avaliar a intensidade da transmissão do dengue em determinados municípios e, também, compará-la a dados obtidos pela vigilância epidemiológica durante a epidemia. No Estado de São Paulo, Brasil, foram realizados dois desses inquéritos, após as primeiras epidemias de dengue ocorridas. Nesses estudos, comparouse a prevalência de indivíduos com anticorpos para dengue com os coeficientes de casos medidos durante a epidemia. Também, foram feitas comparações de dados entre diferentes áreas dos municípios e com relação à infestação por mosquitos vetores, além de abordarem aspectos da vigilância epidemiológica relacionados ao diagnóstico clínico e sorológico do dengue 1,2.

No presente trabalho, estudou-se a epidemiologia do dengue no Município de Campinas, São Paulo, Brasil, realizando, em 1998, um inquérito populacional pós-epidêmico visando à detecção dos níveis de anticorpos para dengue e compa- 
rando esses com dados obtidos pela vigilância epidemiológica durante as epidemias locais de 1996 a 2003. O inquérito foi realizado após registro de três anos de epidemias, e a análise comparativa desses dados permitiu avaliar a intensidade da transmissão e sua distribuição no município, bem como levantar questões sobre os indicadores obtidos por meio da vigilância epidemiológica.

\section{Metodologia}

O inquérito na população do Município de Campinas foi realizado no mês de outubro, quatro meses após a detecção dos últimos casos da epidemia de 1998. O trabalho de campo prolongou-se por quatro semanas. Amostras de sangue foram coletadas por punção digital, armazenadas em papel de filtro e analisadas quanto à presença de anticorpos IgG contra vírus do dengue, dos tipos 1 e 2, e vacinal da febre amarela, por EIA-ICC (Enzyme Immuno-Assay on Infected Cultured Cells), um teste imunoenzimático que utiliza células infectadas como antígeno ${ }^{3}$. Os resultados foram analisados por meio de tabelas de freqüência e de cálculos de prevalência para amostra complexa, testes de diferença de proporções, além de medidas de risco. Os resultados do inquérito foram comparados aos da análise dos dados da vigilância epidemiológica.

\section{Área de estudo}

Campinas é município sede de região e dista, a nordeste, $100 \mathrm{~km}$ da capital São Paulo. Trata-se de município industrializado e importante pólo econômico do país, sofrendo, por essas características, significativas pressões de introdução tanto do vetor como do vírus do dengue.

De acordo com dados da Prefeitura Municipal, a transmissão de dengue, em Campinas, foi identificada, pela primeira vez, em 1996, em níveis muito baixos. Desde então, casos de dengue vêm sendo detectados anualmente, tendo ocorrido duas epidemias com maior intensidade de transmissão nos anos de 1998 e 2002 . No momento, circulam, em Campinas, vírus da dengue dos tipos 1, 2 e 3. Foram registrados dez casos do dengue hemorrágica, sendo um fatal em 2000 e nove, em 2002, com boa evolução.

É importante salientar que o dengue tem apresentado comportamento marcadamente sazonal na região de Campinas.

\section{Planejamento do estudo}

Estudou-se amostra populacional de residentes no município, estratificada proporcionalmente ao tamanho da população de cada distrito de saúde. Os participantes foram selecionados por conglomerado nas casas sorteadas. O tamanho da amostra a ser coletada, de 1.270 indivíduos, foi calculado a partir da população estimada do município para o ano de 1998, 931.922 habitantes, supondo uma prevalência 15 vezes maior do que a incidência de $0,11 \%$, registrada nos dados da Secretaria de Saúde do Município para a epidemia do ano de 1998 e, também, tendo como base o resultado de inquérito realizado em município da região anteriormente 2 . Foram aceitos um valor máximo para prevalência de 2,35\% e um grau de confiança de $95 \%$.

Em cada distrito, foi sorteado um número de quarteirões correspondente ao tamanho da amostra calculada. Dividia-se esse número por três, supondo-se uma média de três pessoas por casa e acrescentava-se mais $10 \%$ para compensar perdas. Fez-se reposição de quarteirões sorteados. Chegando ao quarteirão sorteado, a equipe de campo da Superintendência de Controle de Endemias (SUCEN) contava o número de casas e procedia ao sorteio daquela que seria pesquisada, utilizando fichas numeradas.

Foi realizada ampla divulgação do trabalho no município enfatizando o caráter voluntário da participação das pessoas. Além disso, os selecionados assinaram um Termo de Consentimento $\mathrm{Li}$ vre e Esclarecido, no qual era, também, ressaltada a utilização exclusiva de materiais descartáveis na coleta de sangue. Não houve submissão do estudo a um Comitê de Ética, porque, por ocasião do levantamento, não havia comitês atuantes nas instituições envolvidas.

Nas casas sorteadas, de cada participante, foram coletadas as seguintes informações: sexo, idade, escolaridade, vínculo trabalhista, antecedente de ter tido dengue e em que ano teria ocorrido esse evento, ocorrência de doença febril durante o período da última epidemia, conhecimentos sobre os sintomas da dengue, conhecimento sobre medidas de prevenção do dengue, freqüência da coleta de lixo na residência, necessidade de armazenar água para uso doméstico e higiene pessoal.

Um banco de dados foi criado e analisado no módulo Csample do Epi Info 6.04b (Centers for Disease Control and Prevention, Atlanta, Estados Unidos).

Amostras de sangue dos participantes foram colhidas por punção da polpa digital, sendo armazenadas em papel de filtro, devidamente identificado, a $-18^{\circ} \mathrm{C}$, até serem eluídas para os testes sorológicos. 


\section{Teste sorológico para dengue}

Para diagnóstico sorológico de dengue, utilizouse o EIA-ICC, um teste imunoenzimático que utiliza células infectadas como antígeno 3,4,5,6. Para tanto, cultivou-se, em frascos plásticos estéreis, células do mosquito Aedes albopictus da linhagem C6/36 em meio Leibowitz L15, contendo $6 \%$ de soro fetal bovino, $10 \%$ de solução de fosfato triptose, $100 \mathrm{U} / \mathrm{ml}$ de penicilina e $1 \%$ de estreptomicina. As células foram mantidas, por $24 \mathrm{~h}$, em estufa a $28^{\circ} \mathrm{C}$, em atmosfera úmida, até formarem monocamadas confluentes. Em seguida, os frascos foram infectados com os vírus da dengue dos tipos 1, 2 e febre amarela vacinal $17 \mathrm{D}$, visando ao teste sorológico para esses vírus. Outros frascos foram mantidos sem infecção. Os frascos infectados foram incubados, por seis dias, a $28^{\circ} \mathrm{C}$. Observou-se, nos frascos, o aparecimento de efeito citopático produzido pelos vírus infectantes nas células C6/36. Também, previamente à coleta das células, confirmou-se a infecção viral por teste de imunofluorescência indireta 7,8 .

Células infectadas e não infectadas (controles negativos) foram colocadas em quantidade de $10^{6}$ por $100 \mu \mathrm{l}$ em cada orifício de microplacas plásticas estéreis de 96 orifícios (Falcon, Estados Unidos), respeitando-se a seguinte ordem: células infectadas e não infectadas em colunas de orifícios alternadas. Após incubação overnight a $28^{\circ} \mathrm{C}$, as células foram fixadas às placas com formalina tamponada $\mathrm{pH} 7$ (37-40\% de formaldeído - 100ml, fosfato de sódio dibásico anidro - 6,5g, fosfato de sódio monobásico - 4g a água destilada - 900ml), acrescentando-se $50 \mu$ por orifício. As placas foram incubadas overnight a $4^{\circ} \mathrm{C}$. Posteriormente, os orifícios foram lavados, por quatro vezes, com PBS e foram secados. As placas, prontas para o teste, foram armazenadas a $-70^{\circ} \mathrm{C}$.

Os sangues a serem testados foram eluídos diretamente dos papéis-filtro. Esses papéis foram picados e colocados em tubos, sendo misturados a $1,70 \mathrm{ml}$ de diluente (albumina bovina a $0,5 \% \mathrm{em}$ PBS). Os tubos foram centrifugados por $2 \mathrm{~min}$ a $10.000 \mathrm{~g}$ e deixados em geladeira overnight.

O EIA-ICC propriamente dito foi realizado acrescentando $200 \mu l$ por orifício de uma solução bloqueadora contendo soro de cabra a $3 \% \mathrm{em}$ PBS e incubando-se as placas a $37^{\circ} \mathrm{C}$ por $2 \mathrm{~h}$. Lavaram-se as placas, por três vezes, com Tween-20 a $0,05 \%$ em PBS. Foram acrescentados a orifícios contendo as células previamente infectadas e aos contendo células não infectadas $100 \mu l$ de cada sangue humano analisado, primeiramente na diluição de $1 / 100$, diluído em albumina bovina a $0,5 \%$ em PBS. Incubou-se $1 \mathrm{~h}$ a $37^{\circ} \mathrm{C}$, lavaram- se os orifícios, por três vezes, com PBS Tween e foram acrescentados $100 \mu \mathrm{l}$ a orifícios teste e controle, de imunoglobulina caprina anti-IgG humano conjugada à peroxidase. As placas foram incubadas por $1 \mathrm{~h} \mathrm{a} 37^{\circ} \mathrm{C}$, lavaram-se os orifícios, por três vezes, com PBS-Tween e acrescentou-se o substrato O-fenileno-diamina (OPD). Fez-se a leitura visual das placas após 20min de incubação a $37^{\circ} \mathrm{C}$, comparando-se a cor alaranjada ou amarelo-escura nos orifícios teste com a ausência de cor nos controles.

Selecionaram-se os sangues positivos para o vírus do dengue tipo 1 na diluição 1/ 100 (192 soros), e esses foram testados para os vírus dengue tipo 2 e febre amarela vacinal. Os sangues positivos para dengue tipo 1, dengue tipo 2 e/ou febre amarela foram, também, testados para esses vírus nas diluições 1/500, 1/2mil e 1/8mil.

Os testes sorológicos para dengue tipo $2 \mathrm{e}$ febre amarela visaram a discriminar o vírus do dengue infectante com base naqueles circulantes no país até aquela ocasião (tipos 1 e 2) e, também, a discriminar a infecção vacinal por um vírus da mesma família e que pode reagir de forma cruzada com o dengue em testes sorológicos, o vírus da febre amarela. Dessa forma, participantes do estudo foram considerados com grande probabilidade de infecção por um dos vírus testados quando seus sangues reagiam apenas para aquele vírus ou, quando reagentes para mais de um dos vírus, tinham essa reação positiva em diluição do sangue quatro vezes superior às observadas para com os outros vírus 9 .

\section{Resultados}

Participaram deste estudo 1.260 indivíduos, dos quais foram coletadas e testadas amostras de sangue. Foram coletadas 1.321 amostras, em 61 (4,61\%) delas, por motivos técnicos, não foi possível realizar os testes laboratoriais. A distribuição por sexo, faixa etária e escolaridade desses 61 indivíduos não apresentou diferença quando comparada com a dos 1.260 participantes do estudo. A mesma comparação por Distrito de Saúde de residência não mostrou diferença, a não ser no Distrito Norte, onde a porcentagem de indivíduos foi menor entre as amostras não testadas. Das 1.260 amostras testadas, 192 (15,274\%) apresentaram IgG reagentes. Excluindo seis amostras que apresentaram reação para o antígeno da febre amarela, obteve-se uma prevalência de reagentes para dengue de 14,797\% (IC95\%: 12,413-17,181). Esses valores foram calculados considerando amostra complexa, estratificada por distrito e em conglomerado nas casas, tendo resultado um efeito de desenho de 1,475. 
De acordo com os dados da Secretaria de Saúde do Município, durante a epidemia de 1998, em Campinas, foram notificados 5.350 casos de dengue, o que resulta em incidência de $0,573 \%$ de casos notificados na população do município. Desses casos notificados, $83,1 \%$ tiveram teste sorológico realizado com $24 \%$ de positividade. Portanto, ocorreram 1.072 casos de dengue com confirmação laboratorial, sendo o coeficiente de incidência de casos autóctones com confirmação laboratorial de $0,113 \%$ ou 114,36 casos por 100 mil habitantes. O número de casos importados mais o de autóctones de outros municípios do Estado, notificados no Município de Campinas e confirmados laboratorialmente, representou 2,9\% do total de casos confirmados neste ano. No ano de 1996, foram notificados 255 casos e, no ano seguinte, 599 casos. O número de casos confirmados laboratorialmente nesses anos foi de 24 e 41 respectivamente.

Os dados relativos ao dengue, registrados na Secretaria Municipal de Saúde, estão resumidos na Tabela 1. Os baixos coeficientes de incidência, registrados nos anos de 1996 e 1997, podem ser observados. Em quatro dos anos mencionados, não se cita isolamento de vírus.

Na Tabela 2, colocaram-se os dados de Campinas junto aos dos outros dois municípios do Estado onde foram realizados inquéritos. Observa-se que a positividade dos exames, realizados durante as epidemias, tem relação com a incidência da doença. Essa relação não se repete na prevalência de reagentes encontrada nos inquéritos nem nas razões entre reagentes (número estimado para a população do município) por número de casos notificados nem entre reagentes (número estimado para a população do município) por número de casos confirmados laboratorialmente. A razão entre reagentes por notificados tem valores semelhantes para Santa Bárbara d'Oeste e Ribeirão Preto (São Paulo), sendo bem maior em Campinas. A razão entre reagentes por confirmados laboratorialmente não repete a relação anterior, sendo maior para Santa Bárbara d'Oeste que para Ribeirão Preto. Campinas apresenta essa razão com valores muito mais elevados.

Calculou-se a prevalência de participantes do inquérito que apresentaram anticorpos para dengue (excluindo-se aqueles reagentes para febre amarela) em cada Distrito de Saúde do Município de Campinas (efeito do desenho de 1,475), como mostra a Tabela 3 .

Na Tabela 3, observa-se que as prevalências de amostras reagentes para dengue foram semelhantes nos diversos Distritos de Saúde. A prevalência de amostras reagentes para dengue no Distrito Leste não se mostrou diferente de maneira significante quando comparada a dos outros Distritos: Noroeste (OR = 1,061; IC95\%: 0,58-1,95); Norte (OR = 0,881; IC95\%: 0,49-1,59); Sudoeste (OR = 1,276; IC95\%: 0,73-2,23) e Sul (OR = 0,996; IC95\%: 0,55-1,79).

Na mesma tabela, pode ser observado que os coeficientes de incidência, com base em dados da epidemia e calculados para cada distrito com base na população total de cada um deles, foram diferentes entre si quando analisados pelo teste de diferença de proporções $(\mathrm{p}<0,001)$. Dentre esses coeficientes de incidência, foi significantemente mais elevado o do Distrito Leste quando comparado com cada um dos demais.

O coeficiente de casos notificados na epidemia (número de casos notificados/população do distrito no ano de 1998 x 100) foi significantemente mais elevado no Distrito Leste (Leste - coeficiente $0,85 \%$; Noroeste - coeficiente $0,5 \%$, $\mathrm{p}<0,001$; Norte - coeficiente $0,48 \%, \mathrm{p}<0,001$; Sudoeste - coeficiente $0,45 \%, \mathrm{p}<0,001$; Sul - coeficiente $0,46 \%, p<0,001)$. Quanto ao coeficiente de notificação do Distrito Noroeste, que é o que tem maior valor depois do Distrito Leste, observou-se que ele é apenas significantemente mais elevado que o do Distrito Sudoeste.

Os títulos (recíprocas da diluição) de anticorpos para dengue e febre amarela, observados nos sangues dos participantes, permitiram considerar:

- Provável infecção por dengue tipo 1 - 123 amostras: 103 reagentes, apenas, para dengue tipo 1 com título de 100; 9 reagentes, apenas, para dengue tipo 1 com título de 500; 3 reagentes, apenas, para dengue tipo 1 com título de 2.000; 2 reagentes para dengue tipo 1 com título de 500 e reagentes para dengue tipo 2 com título de 100; 2 reagentes para dengue tipo 1 com título de 2.000 e reagentes para dengue tipo 2 com título de 100; 2 reagentes para dengue tipo 1 com título de 8.000 e reagentes para dengue tipo 2 com título de 500; 1 reagente para dengue tipo 1 com título de 8.000 e reagente para dengue tipo 2 com título de 500 e para febre amarela com título de 100; 1 reagente para dengue tipo 1 com título de $8.000 \mathrm{e}$ reagente para dengue tipo 2 e para febre amarela com título de 100

- Provável infecção por dengue tipo 2-18 amostras: reagentes para dengue tipo 1 com título de 100 e para dengue tipo 2 com título de 500 ;

- Provável infecção por vírus vacinal da febre amarela -2 amostras: 1 reagente para vírus do dengue tipo 1 com título de 100 e para vírus vacinal com título de 500; 1 reagente para vírus tipo 1 e para vírus tipo 2 com título de 100 e para vírus vacinal com título de 500;

- Infecção indeterminada, por dengue tipo 1 e/ ou tipo $2-45$ amostras: 41 reagentes para dengue tipo 1 e para dengue tipo 2 com título de 100; 4 
Tabela 1

Número de casos de dengue no Município de Campinas, São Paulo, Brasil, confirmados laboratorialmente, coeficiente de incidência por 100 mil habitantes e tipos de dengue isolados segundo o ano (1996-2003).

\begin{tabular}{|c|c|c|c|}
\hline Ano & Número de casos & $\begin{array}{l}\text { Coeficiente de incidência } \\
\text { por } 100 \text { mil habitantes }\end{array}$ & Sorotipos isolados \\
\hline 1996 & 2 & 0,22 & - \\
\hline 1997 & 21 & 2,28 & - \\
\hline 1998 & 1.072 & 114,36 & DEN1 \\
\hline 1999 & 42 & 4,41 & - \\
\hline 2000 & 38 & 3,93 & DEN2 \\
\hline 2001 & 536 & 63,90 & - \\
\hline 2002 & 1.246 & 150,62 & DEN1 e DEN3 \\
\hline 2003 & 382 & 44,3 & DEN3 \\
\hline
\end{tabular}

Fonte: Coordenadoria de Vigilância em Saúde, Secretaria de Saúde, Prefeitura Municipal de Campinas.

Tabela 2

Dados de epidemias (incidência, positividade dos exames) e inquéritos populacionais, relacionando número estimado de infectados na população com número de casos notificados e confirmados, em Ribeirão Preto (epidemia - 1991, inquérito - 1992), Campinas (epidemia e inquérito - 1998), Santa Bárbara d'Oeste (epidemia e inquérito - 1995), São Paulo, Brasil.

\begin{tabular}{|c|c|c|c|c|c|}
\hline Município & $\begin{array}{l}\text { Coeficiente de } \\
\text { incidência por } \\
100 \text { mil habitantes }\end{array}$ & $\begin{array}{c}\text { Exames positivos/ } \\
\text { Realizados (\%) }\end{array}$ & $\begin{array}{l}\text { Prevalência do } \\
\text { inquérito (\%) }\end{array}$ & $\begin{array}{c}\text { Número de casos } \\
\text { reagentes/ } \\
\text { Notificados }\end{array}$ & $\begin{array}{c}\text { Número de casos } \\
\text { reagentes/ } \\
\text { Confirmados }\end{array}$ \\
\hline Ribeirão Preto & 0,55 & 40,0 & 5,4 & 2,5 & 6,6 \\
\hline Campinas & 0,11 & 20,0 & 14,8 & 22,1 & 124,1 \\
\hline Santa Bárbara d'Oeste & 0,04 & 12,6 & 0,5 & 2,0 & 15 \\
\hline
\end{tabular}

Fonte: Dados dos inquéritos, Lima et al. 2 e Figueiredo \& Shope 3.

Tabela 3

Prevalência de participantes do inquérito apresentando anticorpos para dengue por Distrito de Saúde do Município de Campinas, São Paulo, Brasil, incluindo, para comparação, a prevalência de anticorpos detectada entre casos suspeitos de dengue durante a epidemia, 1998.

\begin{tabular}{|c|c|c|c|c|c|}
\hline \multirow[t]{2}{*}{ Distrito } & \multicolumn{3}{|c|}{ Inquérito } & \multicolumn{2}{|c|}{ Epidemia } \\
\hline & $\begin{array}{l}\text { Amostras } \\
\text { coletadas }\end{array}$ & $\begin{array}{l}\text { Número de } \\
\text { amostras } \\
\text { reagentes }\end{array}$ & $\begin{array}{c}\text { Prevalência/100 } \\
\text { participantes } \\
\text { (IC95\%) }\end{array}$ & $\begin{array}{l}\text { Número de casos } \\
\text { confirmados (\%) }\end{array}$ & $\begin{array}{c}\text { Coeficiente de } \\
\text { incidência/100 } \\
\text { habitantes (IC95\%) }\end{array}$ \\
\hline Leste & 270 & 41 & $15,18(9,97-20,39)$ & $711(66,32)$ & $0,321(0,28-0,34)$ \\
\hline Noroeste & 194 & 28 & $14,42(8,84-20,03)$ & $102(9,51)$ & $0,074(0,05-0,07)$ \\
\hline Norte & 231 & 39 & $16,87(10,90-22,85)$ & $63(5,88)$ & $0,038(0,03-0,05)$ \\
\hline Sudoeste & 260 & 32 & $12,31(8,13-16,46)$ & $18(1,68)$ & $0,010(0,00-0,02)$ \\
\hline Sul & 302 & 46 & $15,22(9,71-20,73)$ & $178(16,60)$ & $0,078(0,05-0,09)$ \\
\hline Total & 1.257 & 186 & $14,80(12,40-17,17)$ & $1.072(100,00)$ & $0,113(0,11-0,012)$ \\
\hline
\end{tabular}

Fonte: Coordenadoria de Vigilância em Saúde (COVISA), Secretaria de Saúde, Prefeitura Municipal de Campinas. 
reagentes para dengue tipo 1 e para dengue tipo 2 com título de 500;

- Infecção indeterminada, por dengue tipo 1 e/ ou por vírus vacinal de febre amarela - 2 amostras: reagentes para vírus tipo 1 e para vírus vacinal com titulagem de 100;

- Infecção indeterminada, por dengue tipo 2 e/ ou por vírus vacinal de febre amarela - 1 amostra: reagente para vírus dengue tipo 1 com título de 100, para vírus dengue tipo 2 e para vírus vacinal com título de 500;

- Infecção indeterminada, por dengue tipo 1 e/ ou tipo 2 e/ ou vírus vacinal de febre amarela - 1 amostra: reagente para os três vírus com título de 100.

De acordo com a classificação acima, observa-se uma predominâcia significativa do dengue tipo 1 em relação ao tipo $2(\mathrm{p}<0,001)$

A partir de levantamento realizado no Instituto Adolfo Lutz, regional de Campinas, por ocasião deste estudo, sobre amostras colhidas para tentativa de isolamento viral durante a epidemia de 1998 e o resultado deste exame, obtiveramse os seguintes dados: de um total de 264 amostras, em 50 delas (18,94\%; IC95\%: 14,20-23,67), foi isolado o vírus do dengue tipo 1, em 2 delas $(0,76 \%$; IC95\%: $-0,28--1,81)$, foi isolado o sorotipo 2, em 177 (67,04\%; IC95\%: 61,36-72,73), não foram isolados vírus e, para 35 amostras, não se conseguiu recuperar o resultado por motivos variados. Ressalta-se que essas amostras foram colhidas de acordo com orientação do Sistema de Vigilância Epidemiológica para colher amostras para isolamento viral numa parcela dos casos (cerca de $10 \%$ ) que procurou algum serviço de saúde nos primeiros cinco dias após o início da febre. Observou-se, nesses dados, predominâcia significativa do dengue tipo 1 em relação ao tipo 2 ( $\mathrm{p}<0,001$ ). Comparando esses dados com os do inquérito, observa-se que a prevalência do vírus tipo 1 mostra-se mais importante nos dados da epidemia do que nos dados do inquérito ( $\mathrm{p}$ $<0,001)$. Por outro lado, o dengue tipo 2 apresenta-se de maneira mais marcante nos dados do inquérito do que nos dados da epidemia ( $p$ $<0,001)$. Ressalta-se que as duas amostras das quais se isolou o vírus do dengue tipo 2, durante a epidemia, provinham de casos que não foram classificados como autóctones.

Ao serem comparadas as porcentagens de amostras positivas para dengue tipo 1 e tipo 2 dos participantes do inquérito, em cada Distrito de Saúde, foi observado que houve diferença estatística apenas no Distrito Sudoeste, com valor mais elevado para dengue tipo 2 ( $\mathrm{p}=0,01)$. Fazendo-se a mesma comparação com os dados referentes às amostras clínicas de casos suspeitos, submetidas ao isolamento viral, durante a epidemia, observou-se predominância de dengue tipo 1 no Distrito Leste em relação ao tipo 2 ( $p=0,01)$. No outro distrito onde foi conseguido o isolamento de uma amostra de dengue tipo 2, o Noroeste, a diferença entre as porcentagens de amostras positivas para cada um dos sorotipos não foi significativa estatisticamente $(\mathrm{p}=0,19)$. Ressalta-se que, no Distrito Sudoeste, não se obteve isolamento de vírus.

Para os participantes do inquérito, comparou-se, em tabela 2x2, a informação fornecida quanto ao antecedente de vacinação antiamarílica e os resultados do EIA-ICC, sendo os valores encontrados os seguintes: dos 416 participantes que referiram que haviam sido vacinados ou tinham dúvida, 71 foram reagentes (17,07\%), e 345 (82,92\%) não o foram; dos 785 que referiram não serem vacinados, 108 (13,76\%) foram reagentes, e $677(86,23)$ não o foram (OR = 1,29; IC95\%: 0,91$1,83)$; para 59, essa informação não estava disponível. Não se observou, então, diferença entre os grupos de reagentes e não reagentes, de acordo com a informação sobre vacinação antiamarílica prévia. Da mesma forma, não se observou diferença da presença de anticorpos para febre amarela quanto à informação sobre vacinação antiamarílica prévia. $O$ percentual de indivíduos que referiram terem sido vacinados contra febre amarela entre os participantes do inquérito foi de $19,3 \%$, aqueles que tinham dúvida quanto à vacinação representaram $14,3 \%$.

$\mathrm{Na}$ análise comparativa, não se observou associação de sexo e faixa etária com presença de anticorpos para dengue entre os participantes do inquérito (Tabelas 4 e 5). A mesma falta de relação se observou quanto à escolaridade ou vínculo trabalhista.

Comparou-se, também, em tabela 2x2, a informação fornecida quanto ao antecedente de dengue e os resultados do EIA-ICC. Não houve diferença entre os grupos (OR $=2,265$; IC95\%: 0,44-11,76). Análises similares feitas com as informações sobre ocorrência de doença febril durante o período da epidemia contra resultados do EIA-ICC não mostraram diferença significante entre os reagentes e não reagentes. Também, não foram encontradas diferenças significantes entre participantes que tinham coleta de lixo com freqüência diferente ou entre os que necessitavam armazenar água e aqueles que não necessitavam ou, ainda, entre participantes com melhor ou pior conhecimento sobre os sintomas do dengue. Entretanto, quando se analisou conhecimento sobre medidas de prevenção do dengue, encontrou-se diferença significante entre os participantes que referiram não saber sobre elas e aqueles que foram classificados como possuindo conhecimento médio sobre as referidas medidas 
Distribuição dos participantes no inquérito por faixa etária.

\begin{tabular}{|c|c|c|c|c|c|c|c|}
\hline \multirow[t]{3}{*}{ Faixa etária (em anos) } & \multicolumn{6}{|c|}{ Resultado do EIA-ICC } & \multirow[t]{3}{*}{ OR * (IC95\%) } \\
\hline & \multicolumn{2}{|c|}{ Reagente } & \multicolumn{2}{|c|}{ Não reagente } & \multicolumn{2}{|c|}{ Total } & \\
\hline & Número & $\%$ & Número & $\%$ & Número & $\%$ & \\
\hline Ignorada & 1 & 16,67 & 5 & 83,33 & 6 & 100,00 & \\
\hline $0-4$ & 11 & 19,63 & 45 & 80,37 & 56 & 100,00 & \\
\hline $5-9$ & 11 & 15,48 & 60 & 84,51 & 71 & 100,00 & $1,32(0,51-3,51)$ \\
\hline $10-14$ & 13 & 11,61 & 99 & 88,38 & 112 & 100,00 & $1,85(0,75-4,62)$ \\
\hline $15-19$ & 18 & 15,93 & 95 & 84,06 & 113 & 100,00 & $1,28(0,58-2,88)$ \\
\hline $20-24$ & 16 & 17,01 & 78 & 82,98 & 94 & 100,00 & $1,18(0,48-2,93)$ \\
\hline $25-29$ & 15 & 15,30 & 83 & 84,68 & 98 & 100,00 & $1,34(0,59-3,11)$ \\
\hline $30-39$ & 30 & 14,62 & 175 & 85,36 & 205 & 100,00 & $1,42(0,67-3,05)$ \\
\hline $40-49$ & 20 & 11,23 & 158 & 88,75 & 178 & 100,00 & $1,92(0,84-4,42)$ \\
\hline 50 e mais & 51 & 15,59 & 276 & 84,30 & 327 & 100,00 & $1,31(0,63-2,79)$ \\
\hline Total & 186 & 14,80 & 1.074 & 85,20 & 1.260 & 100,00 & \\
\hline
\end{tabular}

EIA-ICC = Enzyme Immuno-Assay on Infected Cultured Cells.

* Calculado tendo como referência o primeiro intervalo (0-4 anos).

Tabela 5

Distribuição dos participantes no inquérito por sexo.

\begin{tabular}{|c|c|c|c|c|c|c|}
\hline \multirow[t]{3}{*}{ Sexo } & \multicolumn{6}{|c|}{ Resultado do EIA-ICC } \\
\hline & \multicolumn{2}{|c|}{ Reagente } & \multicolumn{2}{|c|}{ Não reagente } & \multicolumn{2}{|c|}{ Total } \\
\hline & Número & $\%$ & Número & $\%$ & Número & $\%$ \\
\hline Feminino & 109 & 14,68 & 633 & 85,30 & 742 & 100,00 \\
\hline Masculino & 76 & 14,78 & 438 & 85,20 & 514 & 100,00 \\
\hline Total & 185 & 14,73 & 1.071 & 85,26 & 1.256 * & 100,00 \\
\hline
\end{tabular}

EIA-ICC = Enzyme Immuno-Assay on Infected Cultured Cells.

Valores com OR =0,98; IC95\%: 0,72-1,36.

* Quatro (4) indivíduos sem registro de sexo.

(OR = 1,53; IC95\%: 1,03-2,26), os quais tiveram uma menor freqüência de anticorpos para dengue. Curiosamente, quando se fez essa análise comparativa entre o grupo que "não sabia" sobre medidas de prevenção do dengue e aquele que foi classificado como tendo um conhecimento bom, não se encontrou diferença significante. Entretanto, ressalta-se que esse grupo com resposta classificada como boa incluía um número pequeno de indivíduos.

\section{Discussão}

Como a prevalência de indivíduos apresentando anticorpos para dengue no inquérito foi muito superior à estimada por ocasião do cálculo de tamanho amostral, foram calculados, para o novo valor e efeito de desenho encontrado, o seu grau de confiança, que foi de $95 \%$, e o seu nível de significância, que foi de $5 \%$, evidenciando uma adequada confiabilidade para os dados aqui mostrados.

A prevalência de anticorpos para dengue na população de Campinas, em 1998, mostrou-se mais baixa que a encontrada em outros inquéritos realizados no país, em cidades médias e grandes. Vale registrar que, nesses inquéritos, foi utili- 
zado o teste de inibição da hemaglutinação, cuja sensibilidade e especificidade na pesquisa de IgG para flavivírus são equivalentes às do EIA-ICC 9 . Vasconcelos et al. 10 referem prevalência de infecções por vírus do dengue de 25 a 56\%, com base em inquéritos realizados em cidades desse tipo. A maioria desses inquéritos ocorreram após as primeiras epidemias detectadas 11,12,13,14. Outro inquérito realizado em cidade de grande porte, Salvador, Bahia, Brasil, mostrou prevalência de reagentes sorológicos para dengue ainda mais elevada, com valor de $68,75 \%$, só que, nesse caso, no momento do inquérito, já se havia passado quatro anos de registro de transmissão 15.

A prevalência encontrada em Campinas $(14,797 \%)$ foi semelhante à encontrada em cidades de pequeno porte. Em inquéritos realizados em duas pequenas cidades do Estado da Bahia, após as primeiras epidemias detectadas, foram encontradas prevalências de 11,9 e 17,5\% 9 .

Por outro lado, a prevalência de anticorpos para dengue encontrada em Campinas, quando comparada às de dois inquéritos realizados no Estado de São Paulo, apresenta valor mais elevado. Inquérito realizado no ano seguinte, tendo-se passado mais um verão após a primeira epidemia de dengue, no ano de 1991, na cidade de Ribeirão Preto, que possuia população de 430.312 habitantes naquele ano, mostrou prevalência de $5,4 \% 1$. Em outro inquérito no mesmo ano após a primeira epidemia detectada, realizado em cidade de porte médio, Santa Bárbara d'Oeste (145.266 habitantes no ano de 1995), situada na região de Campinas, observou-se prevalência de $0,63 \% 2$.

Esses dados permitem concluir que as prevalências encontradas nos inquéritos no Estado de São Paulo são inferiores àquelas observadas em municípios de outros Estados do país. Mesmo que a prevalência de Campinas tenha sido próxima àquela dos dois inquéritos acima citados, se levarmos em conta que ao se realizar um inquérito vai obter-se um retrato cumulativo de infecções ao longo do tempo e que provavelmente o tamanho do município tenha, também, influência nessa prevalência, com valores mais elevados nos de maior porte, seria de esperar valores mais elevados para Campinas já que se trata de cidade de grande porte e que apresentou três episódios epidêmicos antes da realização do inquérito.

Os motivos dessas prevalências baixas no Estado de São Paulo necessitam, ainda, ser objeto de investigação. Pode-se questionar se seriam decorrência de condições climáticas. Os níveis mais elevados de transmissão, observados mais recentemente em municípios litorâneos do Estado, poderiam sugerir relação com a pluviosidade e com temperaturas mais elevadas. Po- de-se conjecturar, também, se as prevalências encontradas nos inquéritos teriam relação com o tipo de urbanização ou, ainda, com medidas adotadas de vigilância e controle da transmissão do dengue.

A prevalência de anticorpos encontrada no presente inquérito permite inferir que 137.906 pessoas, no Município de Campinas, foram infectadas por vírus do dengue. Considerando que, na epidemia de 1998, foram notificados 5.350 casos (3,9\% do número acima referido), o número de indivíduos apresentando anticorpos é, portanto, 25,8 vezes maior. Considerando os casos notificados nos dois anos anteriores, nos quais se foi detectada transmissão, o número total de casos notificados no município vai para 6.204, continuando o número de reagentes bem superior ao de notificados, 22,1 vezes. Analisando estudos soro-epidemiológicos realizados no país, nos quais se fez essa comparação, observase grande variação nos valores encontrados. No Município de Prado, Bahia, Brasil, essa relação foi oito vezes maior para soro reagentes que para casos de dengue notificados e, no mesmo estudo, no Município de Ipupiara, Bahia, Brasil, esse valor foi 1,3 vez menor do que o de casos notificados 9 . Como visto acima, esses inquéritos foram feitos após as primeiras epidemias detectadas. Em Fortaleza, Ceará, Brasil 13, foram observados 21 vezes mais indivíduos infectados por dengue no estudo soro-epidemiológico que nos dados com base em casos notificados. Neste município, já se havia detectado transmissão durante quatro anos na ocasião do inquérito, e a razão foi calculada com o número de casos notificados na epidemia de maior porte que antecedeu o inquérito. Nos dois municípios paulistas, essa relação foi de 2,5 vezes para Ribeirão Preto e duas vezes para Santa Bárbara d'Oeste, como visto nos resultados.

No Estado de São Paulo, onde se realizam exames sorológicos (MacElisa) na maioria dos pacientes cujos casos são notificados, é possível comparar o número estimado de indivíduos apresentando anticorpos contra dengue no inquérito com o número de casos confirmados laboratorialmente durante a epidemia. No presente estudo, o número de soro reagentes para dengue é 128,6 vezes maior do que o número de casos confirmados na epidemia, valor que é bem superior aos encontrados em Ribeirão Preto, 6,6 vezes, e aos encontrados em Santa Bárbara d'Oeste, 15 vezes. Somando-se ao número de casos confirmados no ano de 1998 aqueles dos dois anos anteriores, a razão reagentes/confirmados continua elevada, da ordem de 124,1 vezes.

À primeira vista, poderia se concluir pela melhor qualidade da vigilância epidemiológica nos municípios onde a razão entre número estimado 
de casos reagentes por casos notificados é menor. No entanto, essa relação, também, depende de outros fatores, tais como: a ocorrência de epidemias anteriores à última, que serve de comparação; a ocorrência concomitante de epidemias de outras doenças febris com quadro inespecífico e levando a uma notificação aumentada de casos suspeitos de dengue; o percentual de casos com infecção assintomática ou oligossintomática. A avaliação da qualidade da vigilância epidemiológica dos serviços de saúde desses municípios paulistas foge ao escopo deste estudo. No entanto, entre os profissionais da área, Campinas é tido como um município onde existe, relativamente a outros do Estado, uma organização boa dos serviços de saúde coletiva com descentralização, hierarquização, acesso razoável, seguimento de rotinas e profissionais especializados e de carreira. Pensando que Campinas já havia apresentado transmissão em anos anteriores, seria de se esperar um maior número de casos com anticorpos do que Ribeirão Preto e Santa Bárbara d'Oeste, mas, observando-se os coeficientes baixos de incidência dos anos anteriores a 1998, a diferença é intrigante, principalmente quando se leva em consideração que o coeficiente de incidência de casos de Ribeirão Preto, em 1991, foi de 0,55\%, portanto, cinco vezes maior do que o de Campinas no ano de 1998.

A diferença ainda mais importante entre os valores das razões "casos reagentes/casos confirmados na epidemia” apresentada pelos três municípios paulistas mostra mais um desafio à compreensão. Essa razão, além de todas influências sofridas pela razão "casos reagentes/casos notificados", teria relação mais intensa com a especificidade da suspeita clínica. Isso faz supor uma especificidade maior para Ribeirão Preto, intermediária para Santa Bárbara e bem menor para Campinas. Observa-se que essa razão não guarda proporção nem com a incidência nem com o percentual de positividade dos exames realizados.

Deduz-se desses achados que um número expressivo de infecções por dengue no Município de Campinas não foi detectado pela vigilância, associado a isso, uma elevada parcela dos casos notificados não se confirmou laboratorialmente.

No presente inquérito, utilizou-se EIA-ICC, teste de elevada sensibilidade e de fácil execução, mas específico para o grupo dos flavivírus. Dessa maneira, uma parte dos indivíduos considerados reagentes poderia ter anticorpos contra o vírus vacinal ou contra outro flavivírus do grupo. Como foi visto, cerca de $30 \%$ dos participantes no inquérito referiram que haviam sido vacinados ou tinham dúvida quanto a isso. No entanto, co- mo visto, não houve diferença em relação à informação de vacinação contra febre amarela entre os grupos de reagentes e não reagentes.

Uma outra hipótese a ser avaliada é a da ocorrência de circulação importante de outro flavivírus no município. No presente estudo, não foi testada a presença de anticorpos para outros vírus desse gênero. Essa possibilidade pode vir a ser objeto de investigação, e presentemente não se configura como hipótese mais provável, pois, em estudos anteriores nos quais se pesquisou anticorpos contra flavivírus na população de outras regiões do Estado de São Paulo, a prevalência foi de 2,5\% em áreas urbanas antes de registro de transmissão de dengue no Estado e, em outro, realizado após a ocorrência de epidemia de dengue, não foram encontrados anticorpos contra outros flavivírus, à exceção da dengue 1,16.

Outro achado, também instigante, no presente estudo, é que, diferentemente dos outros dois inquéritos realizados no Estado 1,2, neste, não se encontrou uma proporcionalidade entre a prevalência de anticorpos para dengue e a incidência e notificação de casos durante a epidemia nos diferentes Distritos de Saúde da cidade. O Distrito Leste, cuja incidência na epidemia predominou de maneira evidente em relação aos demais, no inquérito, apresentou-se sem essa diferença. Poderia aventar-se que a diferença encontrada na epidemia se devesse a uma maior notificação no Distrito Leste onde se iniciou a epidemia, o que de fato se constata.

Mesmo sabendo-se da baixa especificidade do EIA-ICC para determinação do sorotipo do vírus do dengue, chamou a atenção, nos resultados dos testes, a presença de titulagens elevadas para o sorotipo dengue 2, tendo, em 18 amostras, superado, em mais de quatro vezes, a titulagem para o vírus tipo 1 . O ideal teria sido submeter todas as amostras aos dois sorotipos, pois, dessa maneira, poderia ter se identificado amostras reagentes apenas ao sorotipo 2 , o que indicaria, com maior probabilidade possível, circulação desse sorotipo. No entanto, por motivos alheios a nossa vontade, foi necessário fazer uma triagem com o vírus tipo 1 e titular, em seguida, os reagentes para os dois sorotipos. Supondo que essas 18 amostras sejam de indivíduos infectados pelo sorotipo 2 do vírus do dengue, observa-se que, utilizando esse mesmo critério para supor possível infecção por vírus tipo 1, o distrito que menos notificou, o Sudoeste, é, justamente, o único onde houve predominância do vírus tipo 2; nos demais, não houve diferença na comparação da prevalência dos dois sorotipos. Por outro lado, os achados de isolamento de vírus, durante a epidemia, mostram predominância clara do sorotipo 1. 
Uma hipótese que poderia explicar tais achados é a de que as epidemias que ocorreram nos anos de 1996 e 1997 tenham sido devidas ao sorotipo 2 e em níveis mais elevados do que o detectado. Isso explicaria a prevalência de reagentes, no Distrito Sudoeste, semelhante a dos demais, tendo possível predominância do vírus tipo 2 por ter sido anterior a 1998. Por meio dessa hipótese, também, poderia explicar-se a ausência de relação entre a referência a antecedentes de dengue ou quadro febril no período da epidemia de 1998 e o resultado positivo no inquérito. Na epidemia de 1998, de acordo com essa hipótese, teria predominado o sorotipo 1 , confirmado pelos isolamentos.

No presente inquérito, que utilizou EIA-ICC no teste dos sangues, não foi possível determinar se as amostras reagentes estavam associadas a infecções secundárias ou primárias por dengue, pois esse teste não dispõe de padronização para tanto. Portanto, é possível que alguns participantes, com altos títulos de anticorpos para dengue (acima de 2.000), tivessem sofrido infecção secundária. Entretanto, o maior número de altos títulos foi para dengue tipo 1, e esses indivíduos, na avaliação acima, foram considerados como tendo provável infecção por esse vírus.

Corroboram a hipótese proposta acima os isolamentos de dengue tipo 2 ocorridos em outros municípios do Estado e da região em 1996 e 1997, mesmo sem ter sido isolado o vírus do dengue no Município de Campinas nesses anos.

Em 1998, como visto, os isolamentos de vírus tipo 2 não foram classificados como provenientes de casos autóctones. No entanto, o histórico da doença, em Campinas, nos anos seguintes à epidemia de 1998, também, apóia a hipótese aqui levantada para os achados do inquérito populacional. Em 1999, foram detectados poucos casos de dengue e não foram isolados vírus. No entanto, em 2000, apesar de terem sido detectados também poucos casos, notificou-se um óbito. Foi o primeiro caso de febre hemorrágica do dengue no município, e o isolamento de vírus realizado identificou o sorotipo 2. Esse caso suscitou que fosse identificada a transmissão do dengue tipo 2 com vários casos, com sintomas frustros, diagnosticados no bairro de residência da paciente. Esse episódio sugere que a circulação simultânea dos tipos virais 2 e 1, em Campinas, já vinha ocorrendo e, de maneira importante, levando ao aparecimento de febre hemorrágica em ano que se notificou e confirmou poucos casos de dengue.

Sendo pertinente a hipótese, a prevalência mais elevada de infecções por vírus do dengue tipo 2 entre os participantes do inquérito que nos dados da epidemia e os baixos coeficientes de incidência observados nas epidemias em 1996 e
1997 sugerem que a maioria das infecções ocorridas, nesses anos, não tenha sido detectada pelo sistema de vigilância. É possível que grande parcela dos casos dessas epidemias tenha tido sintomatologia frustra ou mesmo ser assintomática.

A transmissão silenciosa do vírus do dengue também foi sugerida por Teixeira et al. 15 ao realizarem inquérito na cidade de Salvador. Os autores descreveram transmissão não detectada de dengue tipo 1, em um momento em que não havia "confirmação de que este sorotipo estava circulando na cidade, pois ele só havia sido isolado em amostra de um único indivíduo, e a investigação do caso foi inconclusiva quanto a sua autoctonia" 15 (p. 93). Concluíram, então, que o DEN1 já circulava na cidade há algum tempo, intensamente e simultâneo ao DEN2, que era o que se supunha em circulação na cidade de Salvador, com relativamente poucos casos notificados.

Sabe-se que a determinação do tipo de vírus por meio de testes sorológicos, como os aqui utilizados, padece de baixa especificidade, principalmente quando se trata de infecções secundárias 2 , considerando-se aqui a circulação de dois sorotipos e a referência de vacinação antiamarílica em cerca de $20 \%$ dos participantes. No entanto, mesmo que seja deixada de lado a questão da prevalência por sorotipo, a discussão da prevalência de reagentes para dengue, no município e nos diversos Distritos de Saúde, representa um desafio para a compreensão epidemiológica da situação. Comprova-se, pelos dados do inquérito, confrontados com os da vigilância epidemiológica, a complexidade da transmissão do dengue, tornando o trabalho de vigilância epidemiológica uma tarefa árdua. O presente estudo nos mostra o desafio que representa analisar indicadores de transmissão de dengue.

Observou-se, ainda, neste estudo, que o conhecimento de medidas preventivas para o dengue associou-se a menor prevalência de infecção, o que é coerente e poderia ser objeto de investigação específica, levando em consideração, também, dados de infestação domiciliar pelo Aedes aegypti. Entretanto, as outras informações fornecidas não se mostraram diferentes entre os participantes do inquérito. Provavelmente, isso ocorreu pelo pequeno número de indivíduos com infecção por dengue em cada subgrupo analisado.

Os dados aqui mostrados evidenciam a importância da realização de inquéritos populacionais visando à detecção dos níveis de anticorpos para dengue. Esses inquéritos fornecem informações adicionais àquelas obtidas com os casos de dengue detectados durante as epidemias, mostram o real impacto das epidemias com relação ao número de infectados e sugerem tipos de 
dengue circulantes. O presente inquérito populacional alerta para a necessidade de mais estudos sobre indicadores que respaldem a vigilância epidemiológica e, também, sugere ser necessária uma intensificação da vigilância virológica, mesmo nos anos com menor transmissão, para que se possa conhecer melhor os riscos de epidemias e de casos de dengue hemorrágica.

\section{Resumo}

Estudou-se a epidemiologia do dengue no Município de Campinas, São Paulo, Brasil, por meio de um inquérito populacional aleatório realizado em 1998 , visando à detecção dos níveis de anticorpos para dengue, e de dados de vigilância epidemiológica do período de 1996 a 2003, com ênfase na vigilância virológica. Foram coletadas 1.260 amostras, por meio de punção digital, utilizando-se papel de filtro, sendo as amostras testadas pelo teste imunoenzimático em culturas celulares infectadas (EIA-ICC). Observou-se que a prevalência de soro reagentes (14,79\%) é mais baixa que as encontradas em outros inquéritos realizados no país e superior às encontradas em dois inquéritos realizados em cidades do Estado de São Paulo. Detectou-se uma prevalência de soro reagentes muito superior à incidência de casos notificados e confirmados laboratorialmente durante as epidemias de 1996, 1997 e 1998. Não se encontrou proporcionalidade entre a prevalência de anticorpos para dengue e a incidência de casos durante a epidemia nos diferentes Distritos de Saúde da cidade. Sugerem-se um estudo aprofundado do significado dos indicadores de transmissão utilizados em epidemias e uma vigilância virológica mais intensa, principalmente em anos com níveis de transmissão baixos.

Dengue; Vigilância Epidemiológica; Serologia

\section{Colaboradores}

V. L. C. Lima participou da elaboração do projeto, coordenação de sua execução no campo, análise dos dados e redação do artigo. O. Rangel trabalhou na organização e controle de qualidade da coleta de sangue no campo, discussão dos dados e principalmente na parte de estatística. V. R. Andrade colaborou na organização do trabalho de campo desde o sorteio da amostra até a distribuição dos funcionários e discussão dos dados. N. Y. J. Silveira foi responsável pela coordenação dos participantes da Secretaria Municipal de Saúde de Campinas no trabalho de campo, e participou na elaboração da discussão dos dados. S. S. Oliveira contribuiu com o treinamento e supervisão do pessoal de campo na questão da abordagem e da ética da pesquisa e participou da organização dos dados obtidos através das informações coletadas. L. T. M. Figueiredo participou da realização e controle de qualidade dos testes laboratoriais, discussão e revisão do manuscrito. 


\section{Referências}

1. Figueiredo LTM, Owa MA, Carlucci RH, Fabero AL, Mello NVD, Capuano DM, et al. Encuesta serológica sobre el dengue em Ribeirão Preto, São Paulo, Brasil. Bol Oficina Sanit Panam 1995; 118:499-509.

2. Lima VLC, Figueiredo LTM, Correa Filho HR, Leite OF, Rangel O, Vido AA. Dengue: inquérito sorológico pós-epidêmico em zona urbana do Estado de São Paulo (Brasil). Rev Saúde Pública 1999; 33:566-74.

3. Figueiredo LTM, Shope RE. Na enzyme immunoassay for dengue antibody using infected cultured cells as antigen. J Virol Methods 1987; 17:191-8.

4. Igarashi A. Isolation of a Singh's Aedes albopictus cell clone sensitive to dengue and Chikungunya viruses. J Gen Virol 1978; 40:531-44.

5. Singh KR. Propagation of arboviruses in Singh'cells lines. I - Growth of arboviruses in Aedes albopictus and Aedes aegypti cells lines. Curr Top Microbiol Immunol 1971; 55:127-33.

6. Figueiredo LTM, Owa MA, Carlucci RH, Oliveira L. Estudo sobre diagnóstico laboratorial e sintomas do dengue, durante epidemia ocorrida na região de Ribeirão Preto, SP, Brasil. Rev Inst Med Trop São Paulo 1992; 34:121-30.

7. Figueiredo LTM. Uso de células de Aedes albopictus C6/36 na propagação e classificação de arbovírus das famílias Togaviridae, Bunyaviridae, Flaviviridae e Rhabdoviridae. Rev Soc Bras Med Trop 1990; 23:13-8.

8. Schatzmayr HG, Nogueira RMR, Travassos-daRosa APA. An outbreak of dengue virus at Rio de Janeiro. Mem Inst Oswaldo Cruz 1986; 81:245-6.

9. Figueiredo LTM, Simões MC, Cavalcante SMB. Enzime immunoassay for the detection of dengue IgG and IgM antibodies using mosquito cells as antigen. Trans R Soc Trop Med Hyg 1989; 83:702-7.
10. Vasconcelos PFC, Mota K, Straatmann A, SantosTorres S, Travassos-da-Rosa APA, Tavares Neto J. Epidemia de dengue em Ipupiara e Prado, Bahia: inquérito soro-epidemiológico. Rev Soc Bras Med Trop 2000; 33:61-7.

11. Figueiredo LTM, Cavalcante SMB, Simões MC. Encuesta serológica sobre el dengue entre escolares de Rio de Janeiro, Brasil, 1986 e 1987. Bol Oficina Sanit Panam 1991; 111:525-33.

12. Vasconcelos PFC, Lima JWO, Raposo ML, Rodrigues SG, Travassos-da-Rosa JFS, Amorim SMC, et al. Inquérito soro-epidemiológico na Ilha de São Luís durante epidemia de dengue no Maranhão. Rev Soc Bras Med Trop 1999; 32:171-9.

13. Vasconcelos PFC, Travassos-da-Rosa ES, Travassos-da-Rosa JFS, Freitas RB, Dégallier N, Rodrigues SG, et al. Epidemia de febre clássica de dengue causada pelo sorotipo 2 em Araguaina, Tocatins, Brasil. Rev Inst Med Trop São Paulo 1993; 35:141-8.

14. Vasconcelos PFC, Lima JWO, Travassos-da-Rosa APA, Timbó MJ, Travassos-da-Rosa ES, Lima HR, et al. Epidemia de dengue em Fortaleza, Ceará: inquérito soro-epidemiológico aleatório. Rev Saúde Pública 1998; 32:447-54.

15. Teixeira MG, Barreto ML, Costa MCN, Ferreira LDA, Vasconcelos P. Dinâmica de circulação do vírus da dengue em uma área metropolitana do Brasil. Epidemiol Serv Saúde 2003; 12:87-97.

16. Figueiredo LTM, Travassos-da-Rosa APA, Fiorillo AM. Níveis de anticorpos para arbovírus em indivíduos da região de Ribeirão Preto, SP (Brasil). Rev Saúde Pública 1986; 20:204-11.

Recebido em 29/Dez/2005

Versão final reapresentada em 24/Mai/2006 Aprovado em 03/Jul/2006 